6-17-2020

\title{
Encuesta de conocimientos, actitudes y prácticas del COVID-19: Informantes clave en 10 municipios con población indígena de Guatemala
}

Population Council

Follow this and additional works at: https://knowledgecommons.popcouncil.org/departments_sbsr-pgy

Part of the International Public Health Commons, and the Social and Behavioral Sciences Commons How does access to this work benefit you? Let us know!

\section{Recommended Citation}

"Encuesta de conocimientos, actitudes y prácticas del COVID-19: Informantes clave en 10 municipios con población indígena de Guatemala," COVID-19 Research \& Evaluations presentation. Guatemala City:

Population Council, 2020. 


\section{POPULATION}

\section{COUNCIL}

Ideas. Evidence. Impact.

ENCUESTA DE CONOCIMIENTOS, ACTITUDES

Y PRÁCTICAS DEL COVID-19

INFORMANTES CLAVE EN 10 MUNICIPIOS

CON POBLACIÓN INDÍGENA DE GUATEMALA

Population Council

Mayo 2020 


\section{Encuesta COVID-19 (1)}

- Municipios con población indígena priorizados por el riesgo que implica la exclusión económica y social frente a la emergencia actual del COVID-19

- Encuestas telefónicas recolectadas con informantes clave del 23 al 28 de abril

- Muestra cualitativa de 144 informantes clave

- Elegidos por contactos con mentoras

- 10 municipalidades: Chisec, Patzún, San Andrés Semetabaj, San Juan Ostuncalco, San Juan Sacatepéquez, San Pedro Carchá, Santa María Chiquimula, Totonicapán, Uspantán y Sololá 


\section{Encuesta COVID-19 (2)}

- Perfiles de informantes clave seleccionados

- Líderes del COCODE

- Personal de salud (comunidad y cabecera)

- Personal de escuelas

- Oficiales de la municipalidad

- Delegada Defensoría de la Mujer Indígena

- $100 \%$ han escuchado/saben algo sobre el COVID-19 


\section{Perfiles de informantes clave $(\mathrm{N}=144)$}

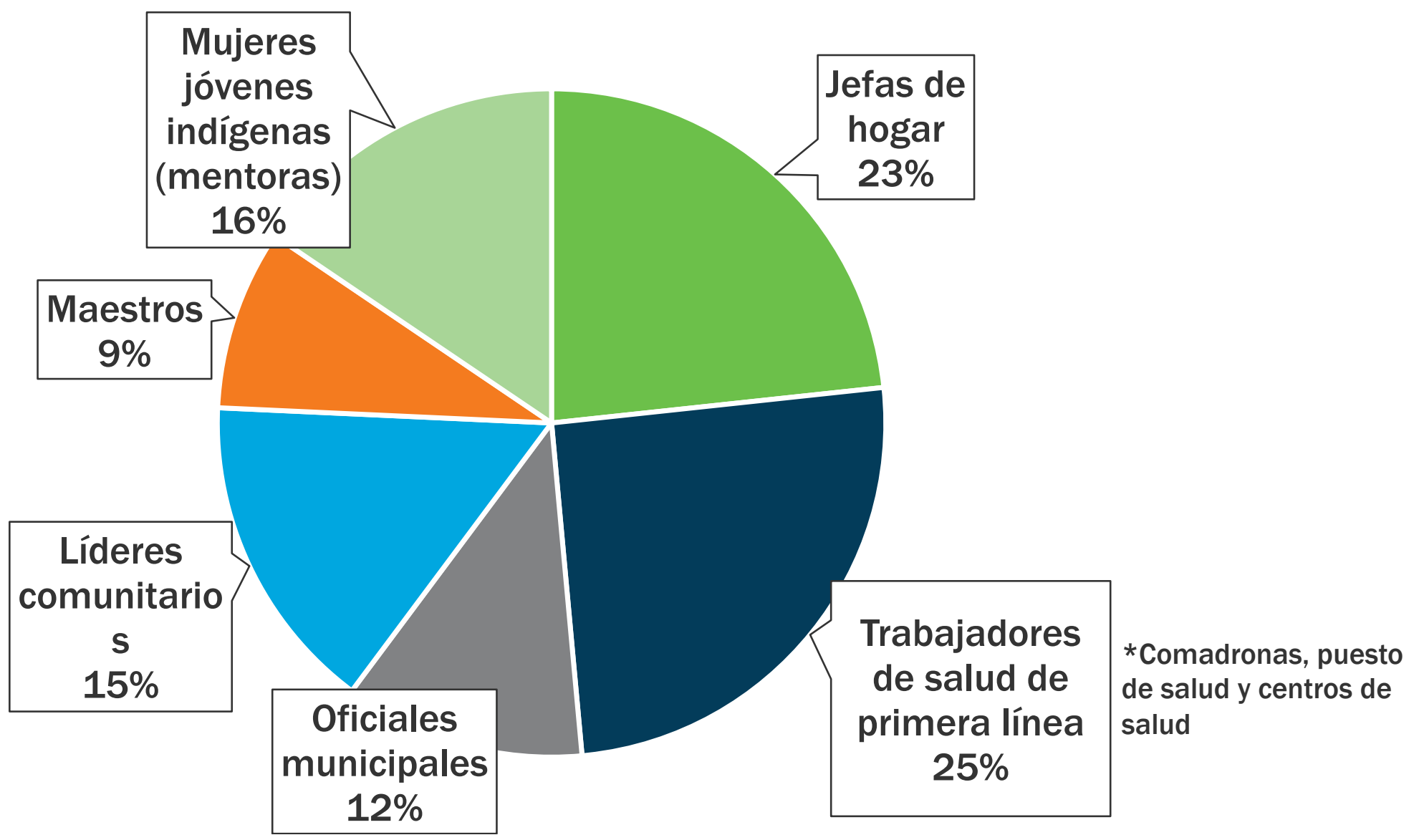

* Oficinas de la mujer y juventud 


\section{¿Quiénes tienen un alto riesgo de enfermarse gravemente si contraen el Coronavirus?}

100

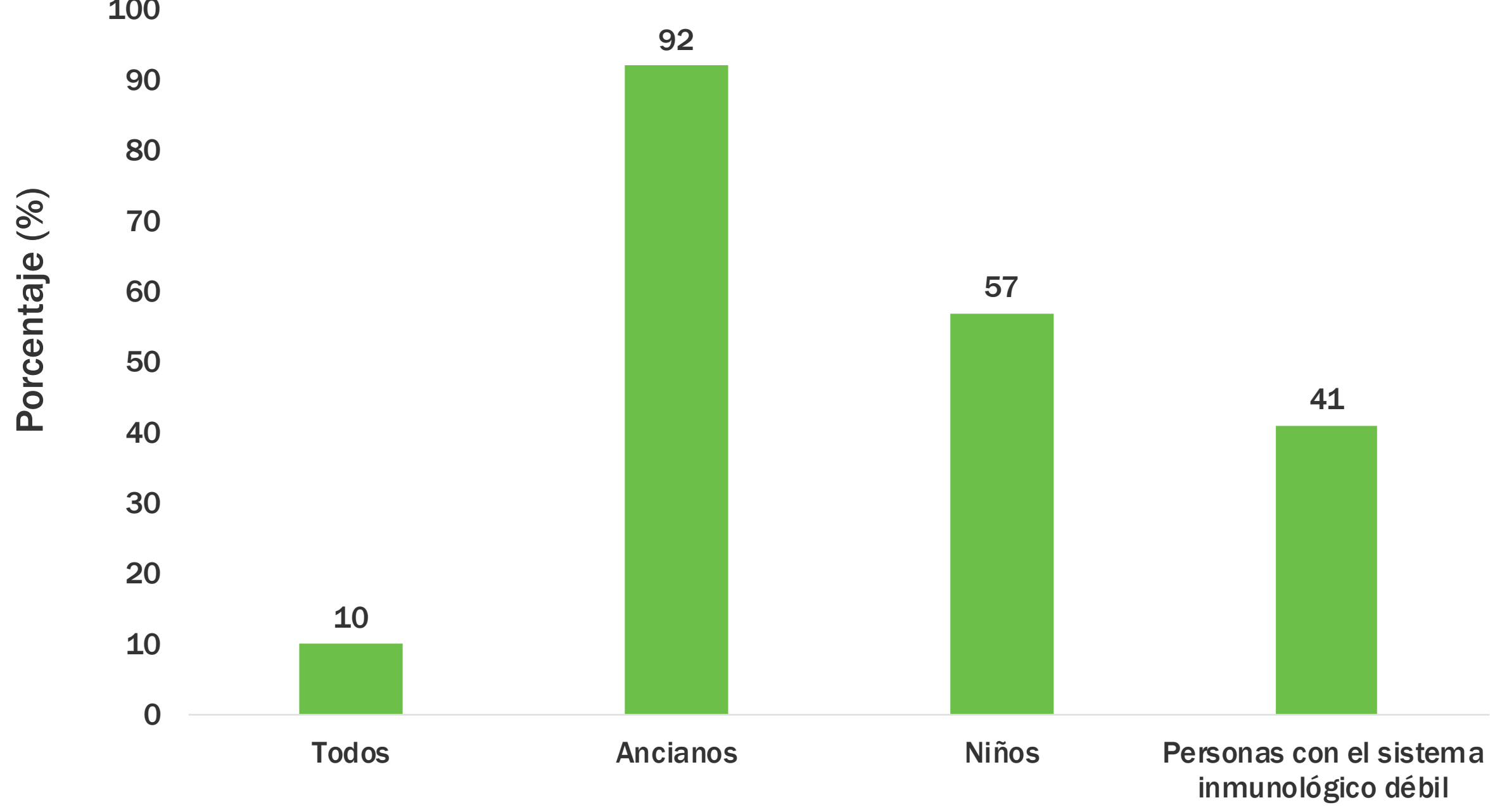




\section{¿Cuáles son los síntomas del COVID-19?}

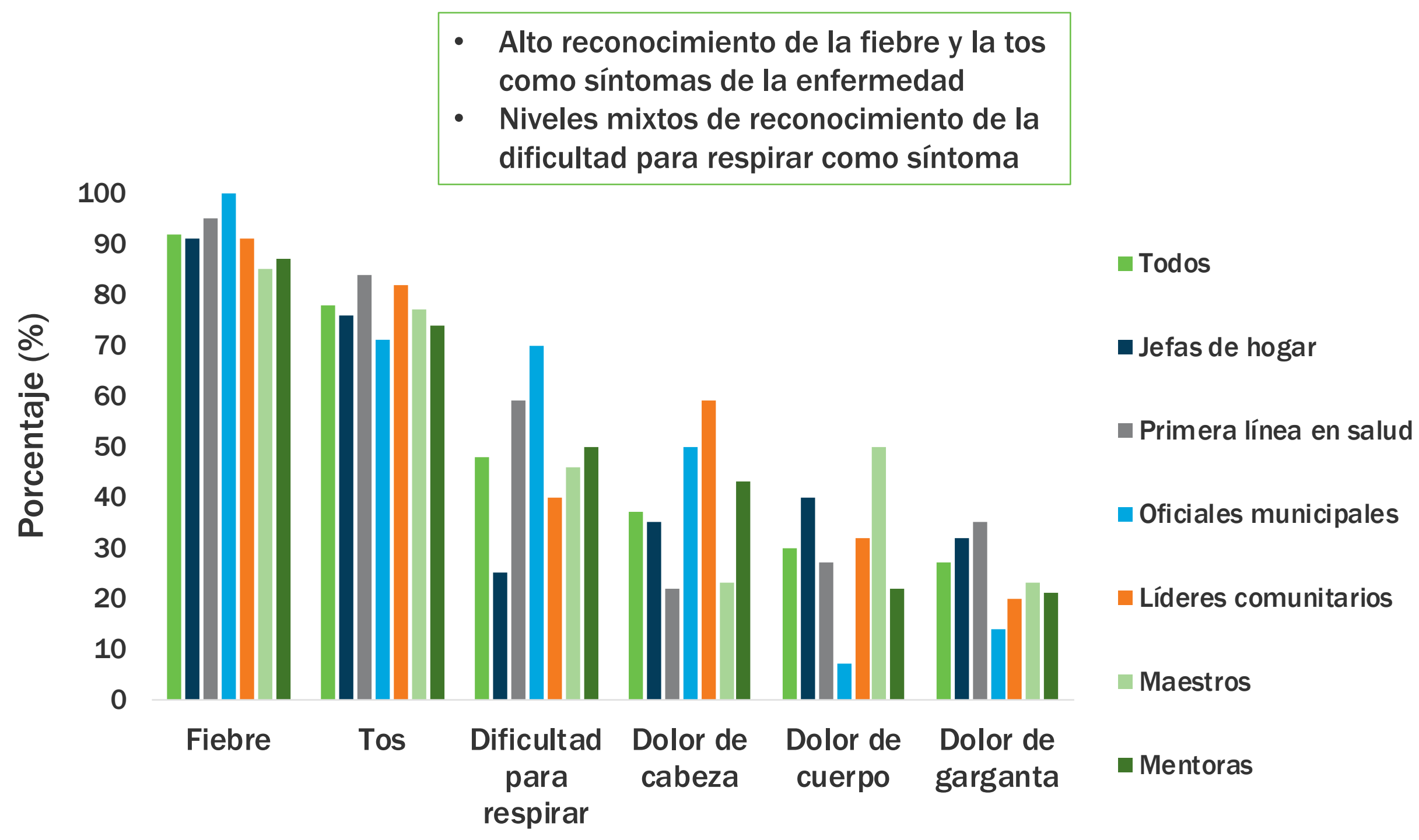




\section{¿Cómo puede prevenirse la infección?}

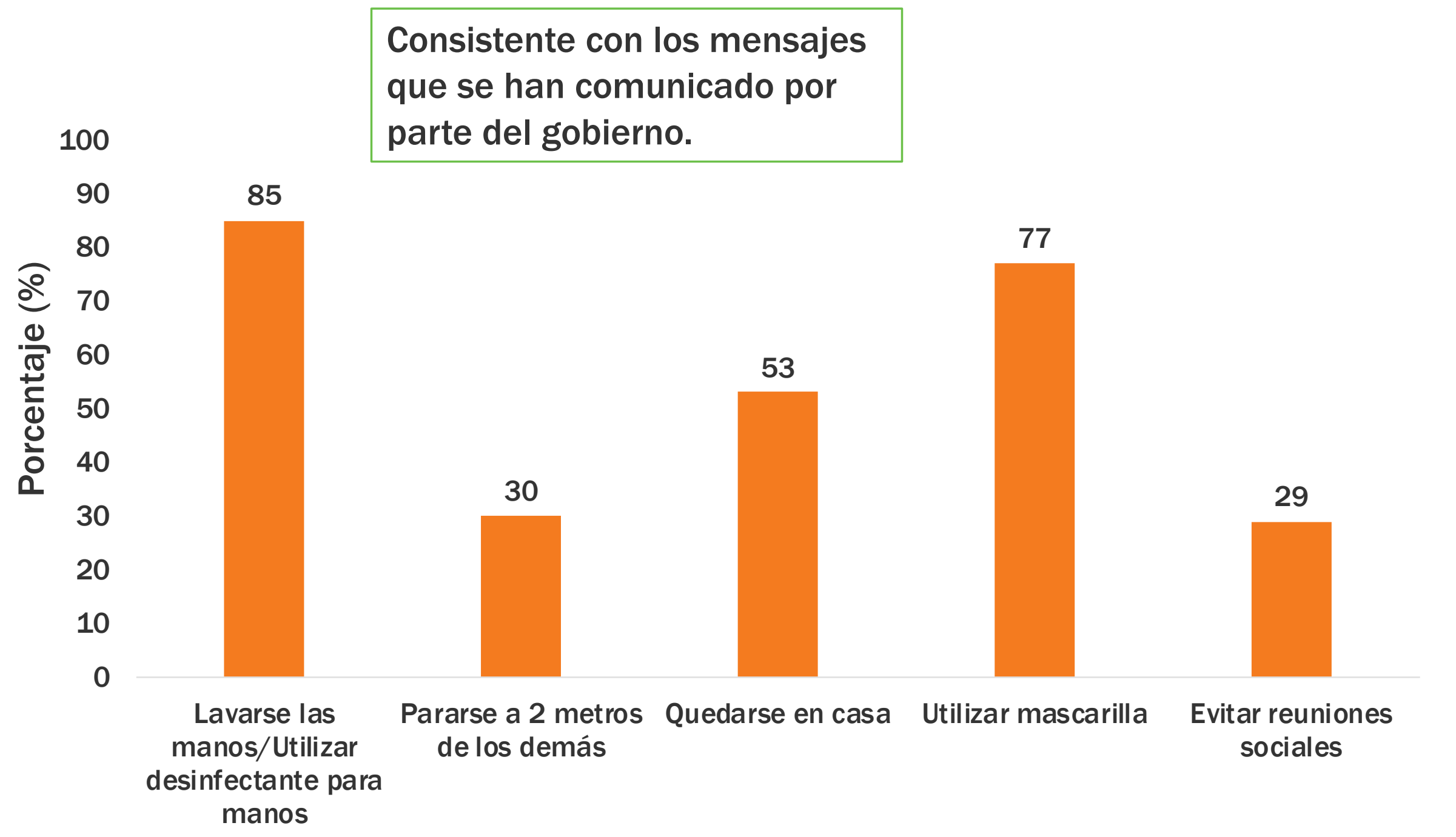




\section{Percepción de la posibilidad de}

infección:

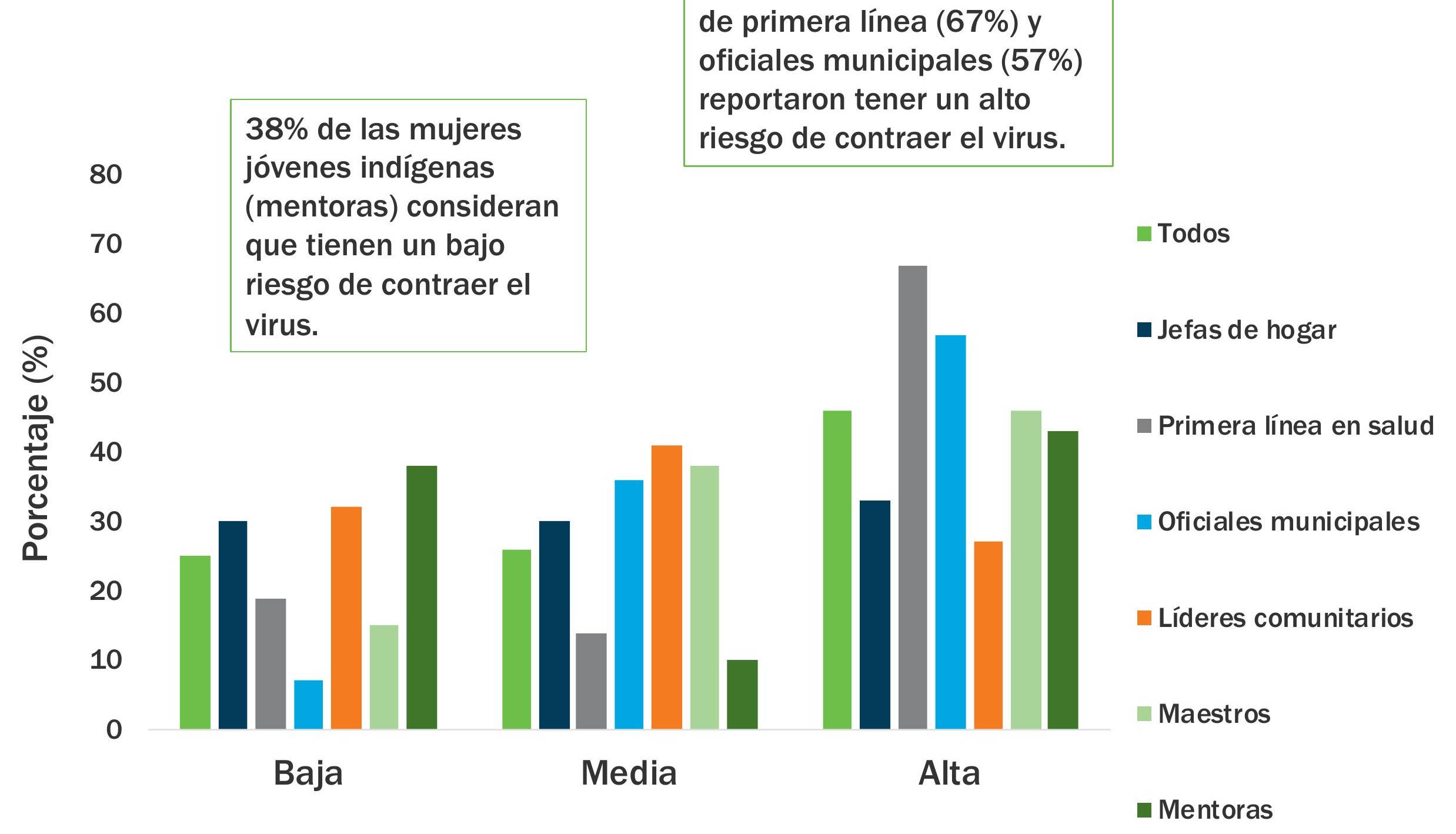

Más trabajadores de salud de primera línea (67\%) y oficiales municipales (57\%) reportaron tener un alto riesgo de contraer el virus. 


\section{Grupos que se han quedado más en casa la semana pasada en comparación con hace \\ un mes:}

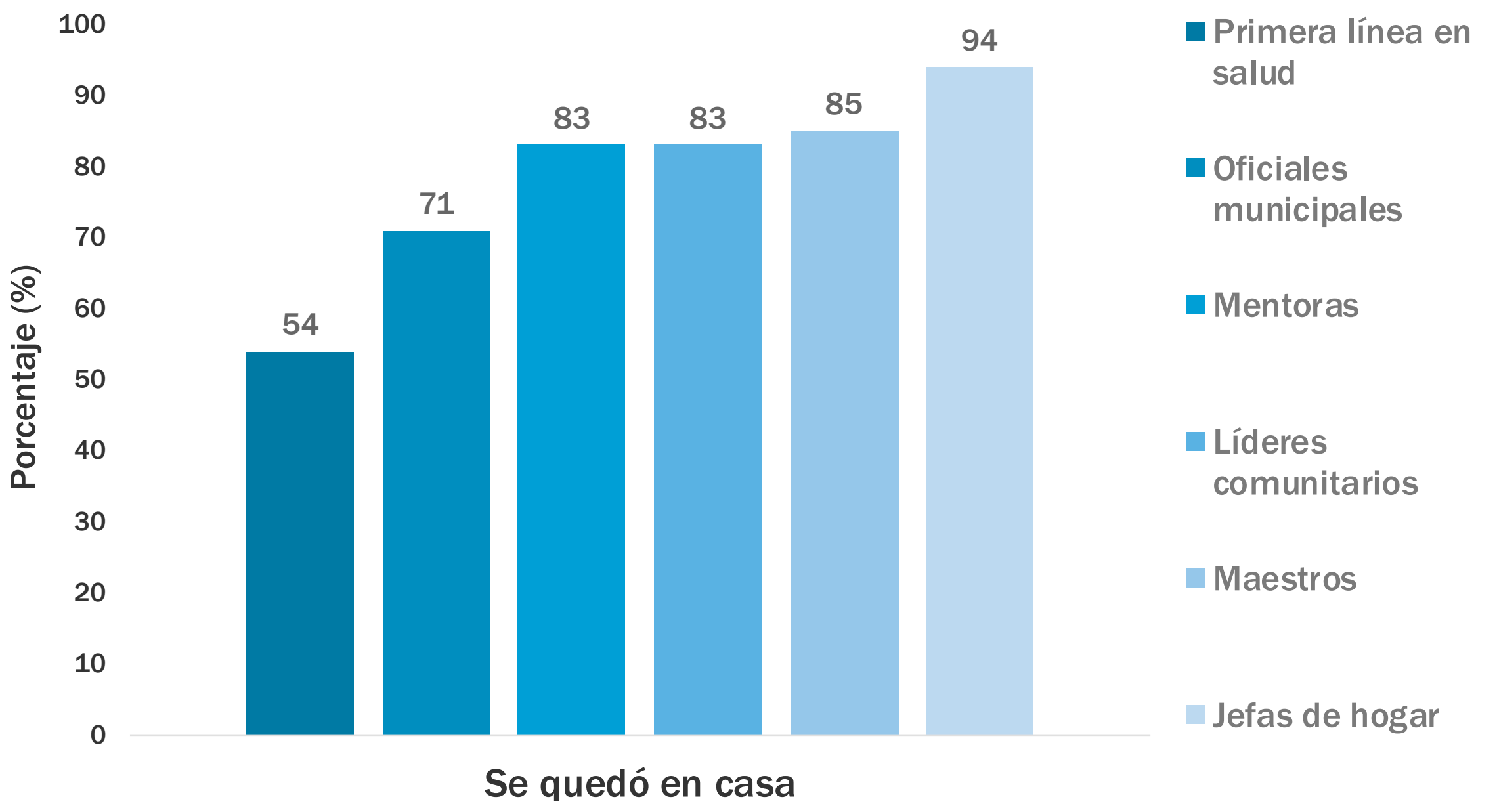




\section{¿Por qué cree considera que tiene pocas posibilidades de infección?}

100

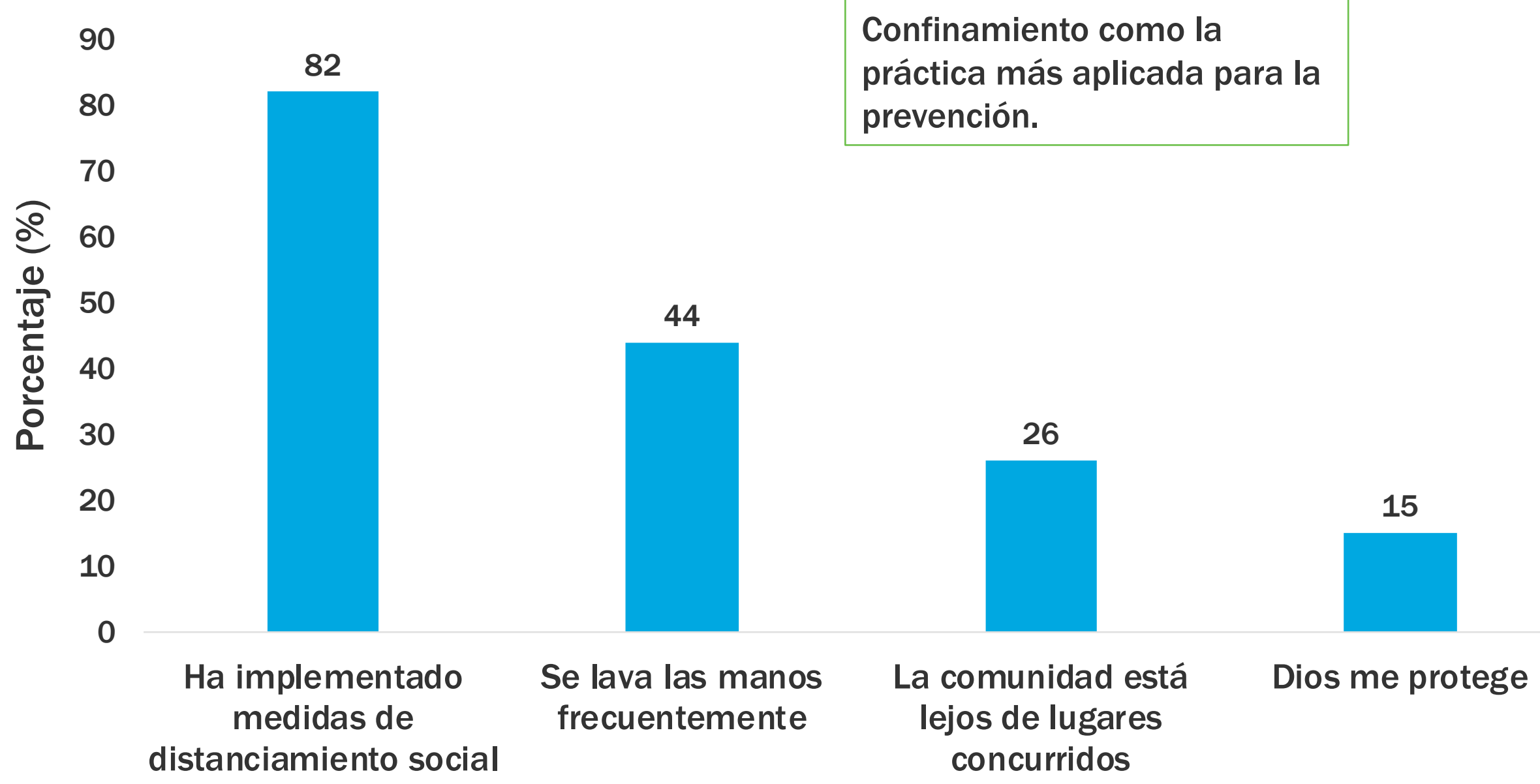




\section{Principales preocupaciones sobre la crisis del Coronavirus:}

100

90

80

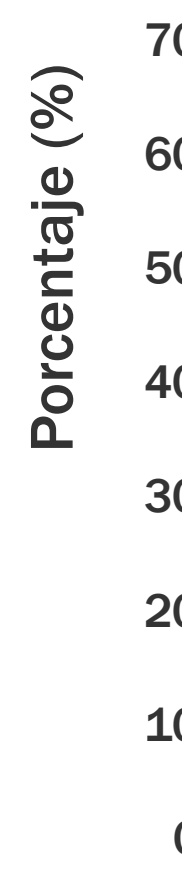

0

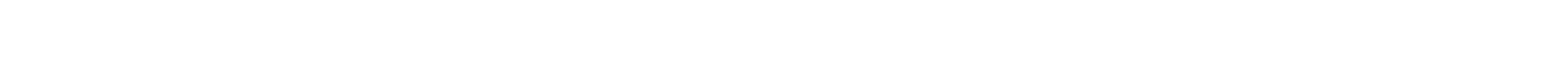

Todos

- Jefas de hogar

- Primera línea de salud

- Oficiales municipales

- Líderes comunitarios

Maestros

- Mentoras
Infectará a los La muerte demás
La pérdida de ingresos

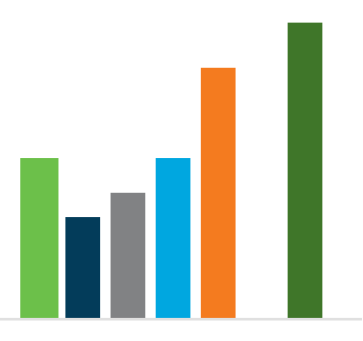

La escasez de comida 


\section{Fuentes de información sobre el Coronavirus en las que más confía:}

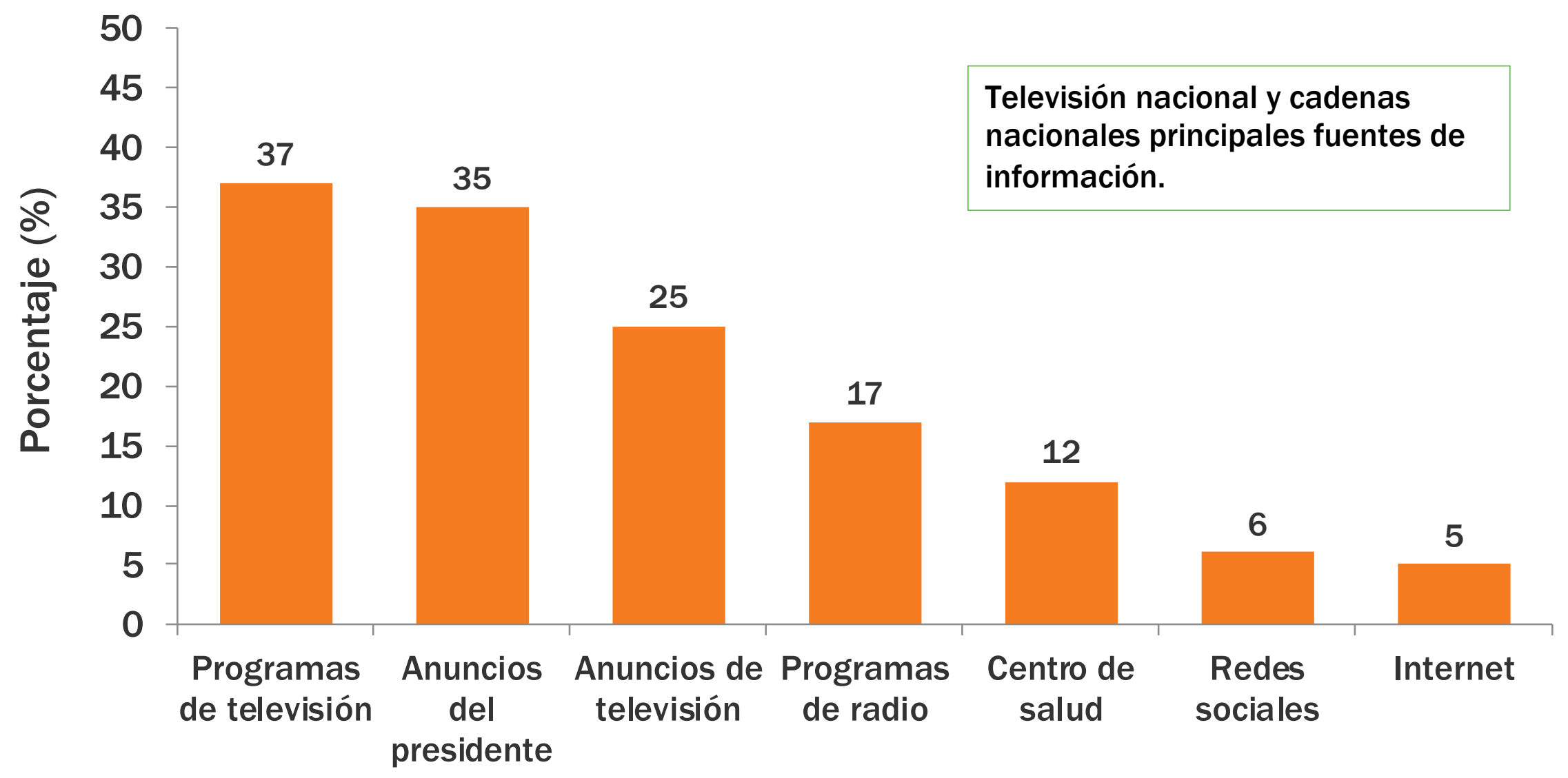




\section{Si tuviera síntomas de COVID-19, ¿qué haría?}

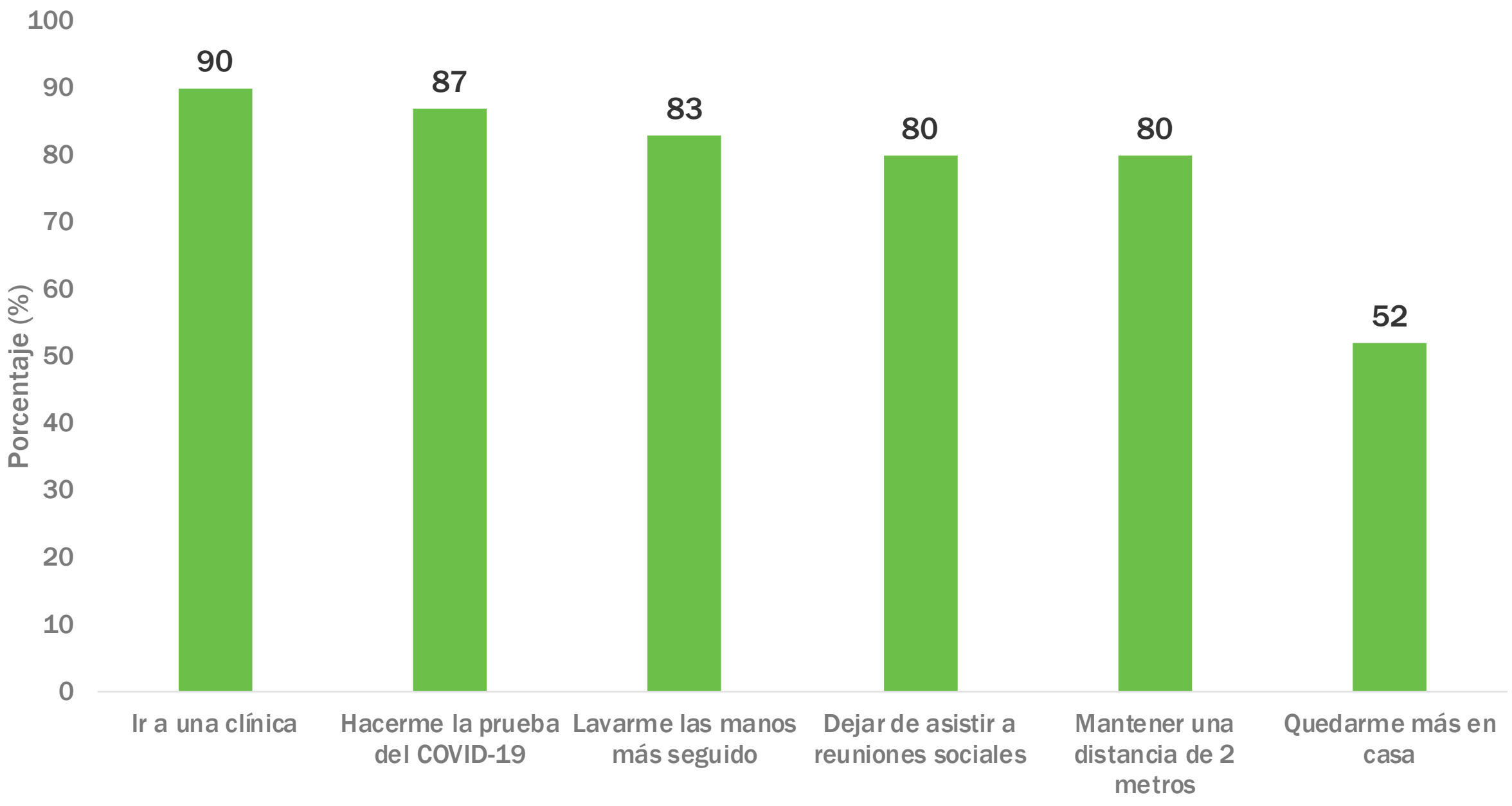




\section{¿Cuáles son los desafíos de su comunidad para guardar cuarentena?}

60

50

40

38

$56 \%$ de los participantes

piensan que los miembros de

su comunidad podrían

quedarse en casa por 14 días si fuese requerido.

$\frac{\sqrt{0}}{\frac{0}{\pi}}$

30

30

20

10

0

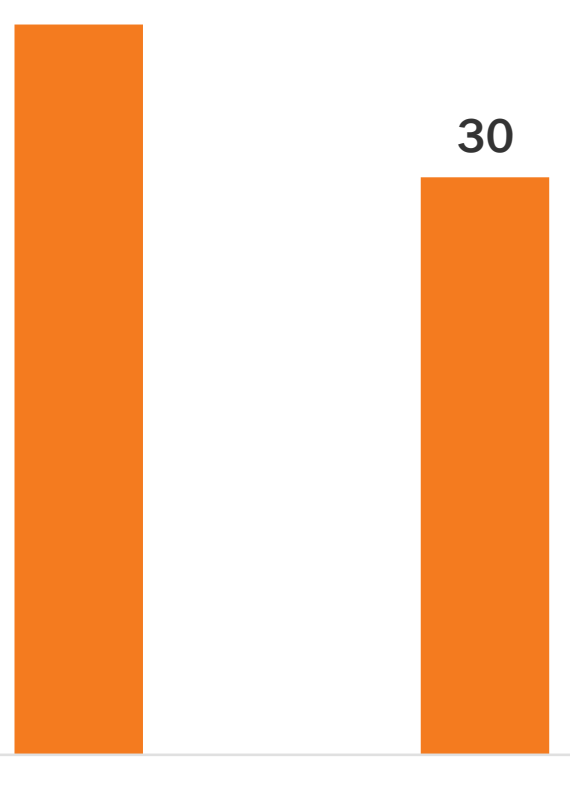

Las familias viven No pueden perder en casas de un solo sus ingresos cuarto

Necesitan hacer No hay dinero para mandados/pagar los servicios alquilar un lugar para autoaislarse
19

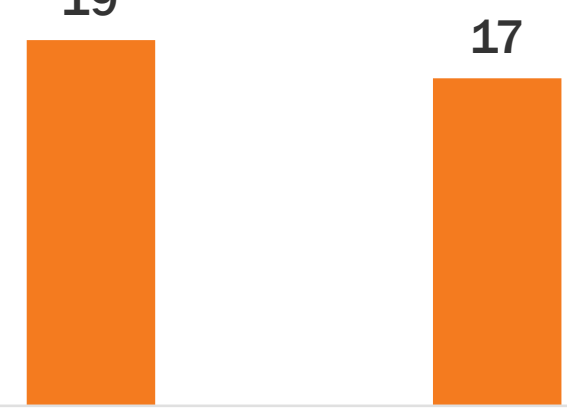

Las familias comparten un solo baño 


\section{¿Cuáles son los desafíos de su comunidad para lavarse las manos frecuentemente o usar desinfectantes para manos?}

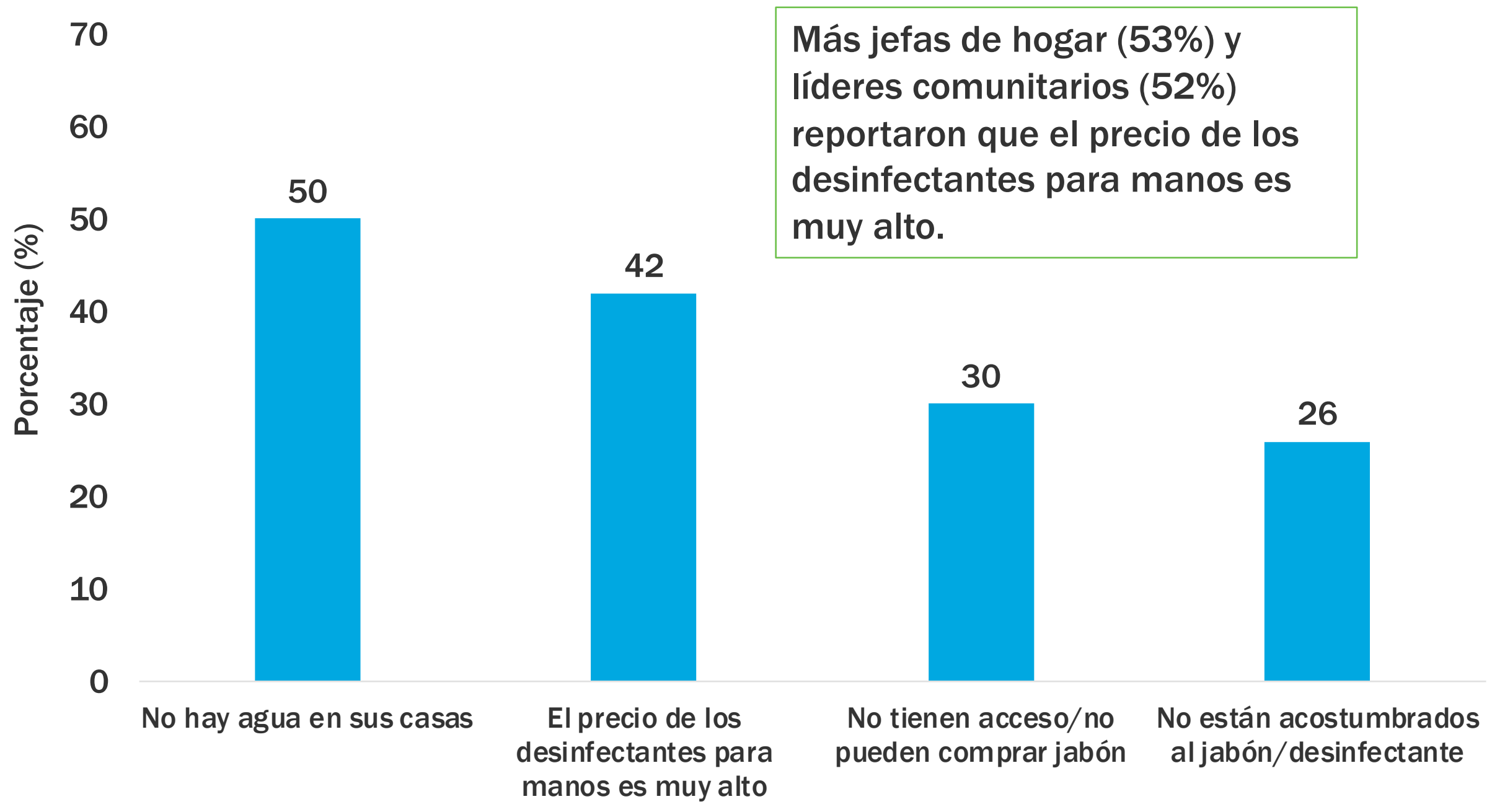




\section{Si el gobierno le dijera que permanezca en su casa durante las próximas dos semanas, ¿cuáles serían sus necesidades críticas?}

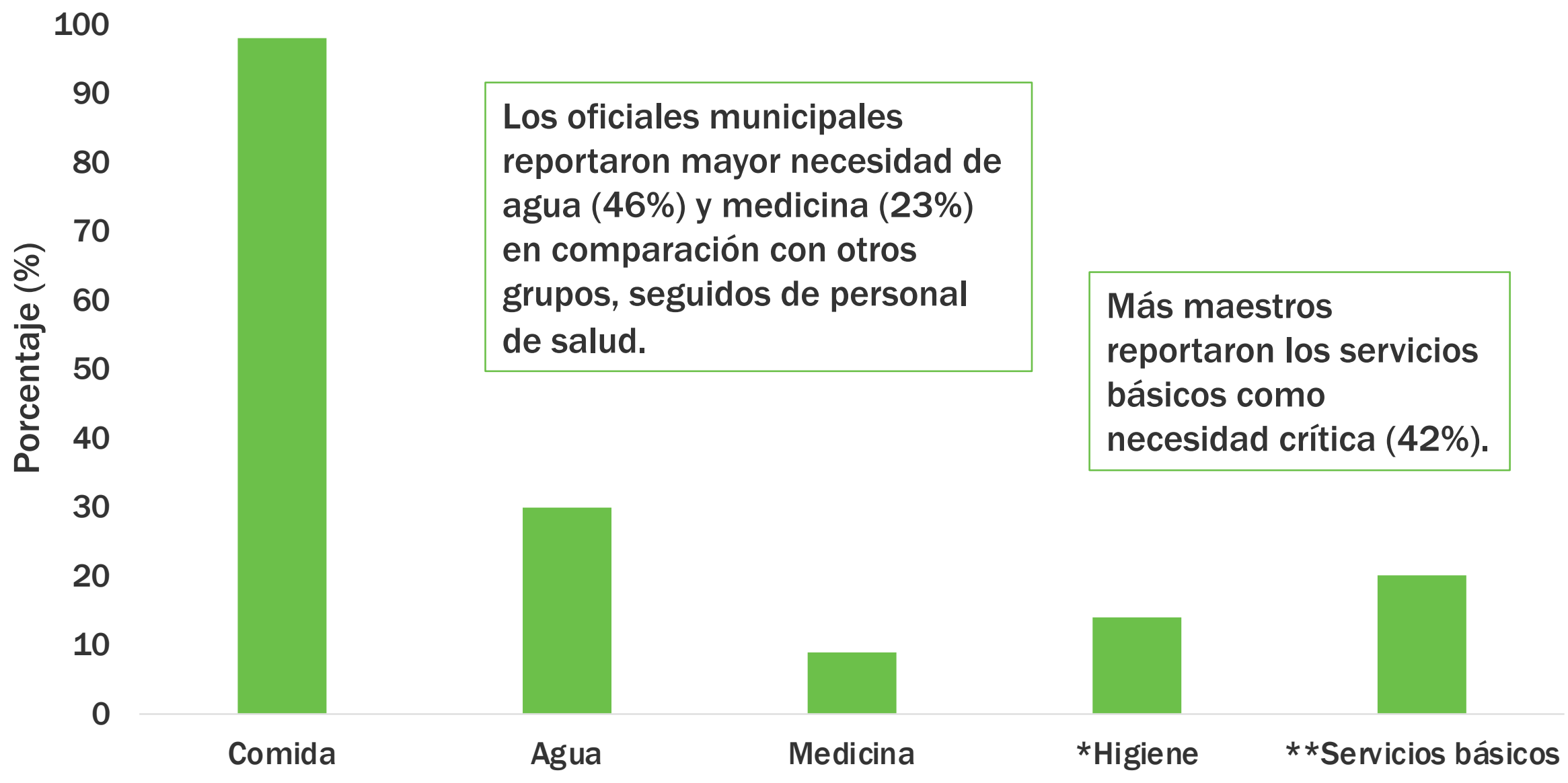

*Higiene (higiene personal y productos de limpieza)

* *Servicios básicos (electricidad, agua, vivienda y recolección de basura) 


\section{Recomendaciones (1)}

- El gobierno central y municipal debe intensificar esfuerzos y proporcionarle información actualizada sobre la prevención del COVID-19 a las comunidades indígenas, enfocándose en:

- Aclarar los síntomas para reconocer la enfermedad y las poblaciones que enfrentan mayor riesgo, con enfoque multilingüe.

- Desarrollar una ruta de acción comunitaria una vez identificado el primer caso, considerando alternativas de aislamiento para los hogares más pobres que no tienen los recursos necesarios.

- Involucrar a los líderes comunitarios, maestros, comadronas en la ruta de acción comunitaria. 


\section{Recomendaciones (2)}

- Prepararse para responder al impacto de la inseguridad alimentaria y la pérdida de ingresos en el corto y mediano plazo.

- Garantizar a las comunidades indígenas el acceso a productos de higiene y medicamentos.

- Proveerles equipo protector personal a los trabajadores de salud de primera línea y a los oficiales municipales, quienes enfrentan mayor riesgo de infección al no poder quedarse en casa. 


\title{
Para más información:
}

\author{
Ángel del Valle, adelvalle@popcouncil.org \\ Representante de país \\ Population Council Guatemala
}

En asociación con los ministerios nacionales de salud y otras agencias gubernamentales en África subsahariana, Asia meridional y América Latina, los científicos de Population Council de todo el mundo y del país están llevando a cabo investigaciones de salud pública y ciencias sociales alrededor del COVID19 para producir evidencia relevante y oportuna para apoyar a los formuladores de políticas para controlar la propagación del coronavirus, evaluar la efectividad de las medidas de prevención y mitigación, y evaluar los efectos sociales, económicos y en la salud a largo plazo de la pandemia.

Cita sugerida: "Guatemala Indigenous Municipalities: COVID-19 Knowledge, Attitudes, and Practices." COVID-19 Research and Evaluations Project. 2020. Guatemala: Population Council.

(C) 2020 The Population Council, Inc. 